\title{
The Role of Contour Line in Painting — an Analysis of Morandi's Still Life Painting
}

\author{
Jingru Liu, Mengqi Jin \\ College of Art, Zhejiang Normal University, Jinhua 321004, Zhejiang, China \\ DOI: $10.32629 /$ asc.v2i4.564
}

\begin{abstract}
In painting, line is one of the basic compositional elements and an important "tool" for artists to express their ideas. The combination of line and color, composition, and shape allows the viewer to feel the author's thoughts, emotions, or distinctive thinking through the picture. Foreign cave paintings, European pre-Renaissance oil paintings and modern paintings, and domestic Dunhuang murals, silk paintings of the Warring States period and cave paintings all show that the contour line has never disappeared despite its different roles in the changing times. Therefore, the artist's generalized expression of contour lines can become a characteristic of the picture that makes the artist stand out.
\end{abstract}

Keywords: contour line, expression, Morandi

\section{Definition of contour line}

Before trying to analyze the meaning of contour line, we should first explore the meaning of contour, which is the edge, the outer circumference of an object or the outer frame of a figure, so I think the contour line should be the edge boundary of the object in the picture composition, the dividing line between the object and the background, between one object and another object, and we have the contour as part of the thing objectively. Da Vinci defined the contour line in "Da Vinci on Painting" as: the outline that surrounds the shape of the object, called the contour line, for example, Neolithic pottery, Warring States silk paintings, silk books of Wei, Jin and North and South Dynasties, literati paintings in Chinese paintings, Dunhuang frescoes, cave frescoes, and these are typical representative works of preserving contour lines in Chinese art works.

Through the analysis of the contour line, I found that the contour line highlights the visual properties of the line, the line is a human primitive instinct to perceive things, art creators use different painting language to inductively express the form of the object and its demeanor or even abstract transformation to complete the creation, "line" is a vital element in the picture, but also human wisdom The "line" is a crucial element in the picture, and is the crystallization of human wisdom.

\section{The role of contour lines}

\subsection{Defining role}

From ancient times to the present, the definition of the contour line is the most common and the biggest role in the picture, it can define the size and shape of the object and the space occupied by the object in the picture. Because through the process of transforming visual experience into mental experience into memory, one's subconscious mind can identify what kind of image is the image through the contour line of the object, and therefore, the contour line is a key factor when one remembers the object.

We can observe Morandi's paintings from 1912 to 1916 (Figure 1), and we can see the defining role of contour lines everywhere, and under the influence of Cézanne, the emphasis on contour lines is clearly visible. By depicting the contour lines, the purity of the color is attached to the contour lines, separating the fruit from the wine glass, so that the viewer can more quickly capture his portrayal of the fruit and experience Morandi's originality in the creation of oil paintings, and the vagueness of the different still life contour lines and their shades of

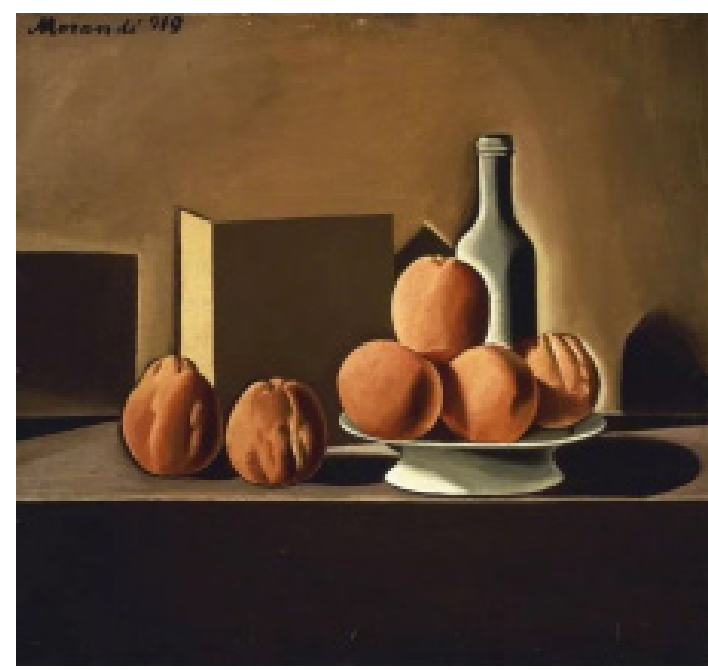

Figure 1. Morandi's painting A 
color make the picture more clear and vivid.

\subsection{Inductive role}

The line is not only a means of modeling, but also an abstract expression of the artist's vision. In the "Six Methods" of the Southern Qi court painting theorists, the "bone method of brushwork" embodies the expressive role of the line, adding strength to the beauty of the composition and injecting the spirit of the object. In Western painting, the expressive role of the contour line is usually reflected in the structural transitions within the object and the unity between the object and the background, and the contour line usually breaks the visual calm and brings a dynamic momentum to the picture.

The line is an important support for the shape, and when Morandi's early works are put together with his mature works, it is not only the difference between figuration and abstraction, but also the simplification and generalization of the shape by Morandi. In his early works (Figure 2), it can be seen that Morandi used color more to outline the shape, looking for dark colors that can present a three-dimensional effect, while in his later works, it can be seen that Morandi mastered shading, and with the change of hue, he began to try to squeeze out the shape with color (Figure 3 ), using dark colors to make light colors more prominent in front of the viewer's eyes. Thus, he achieved the effect that the picture was integrated and had a more holistic view of the overall situation. In the works of Morandi's mature period, we can find that his generalized expression of the geometry of the objects has reached a considerable height, and the individual characteristics of the objects in his works are cleverly integrated with his generalized geometry of the objects, making his works unique in terms of shape. In this period, Morandi not only focused on the shape of individual objects, but also explored and studied all the objects in the picture and the surrounding environment together, so as to form a harmonious and unified atmosphere at the level of modeling, which is very useful for the viewer to form an objective sense of space in the overall picture, which is what Arnheim mentioned in "Visual Thinking" as " Perceptual Sensing - Compulsory Complementation".

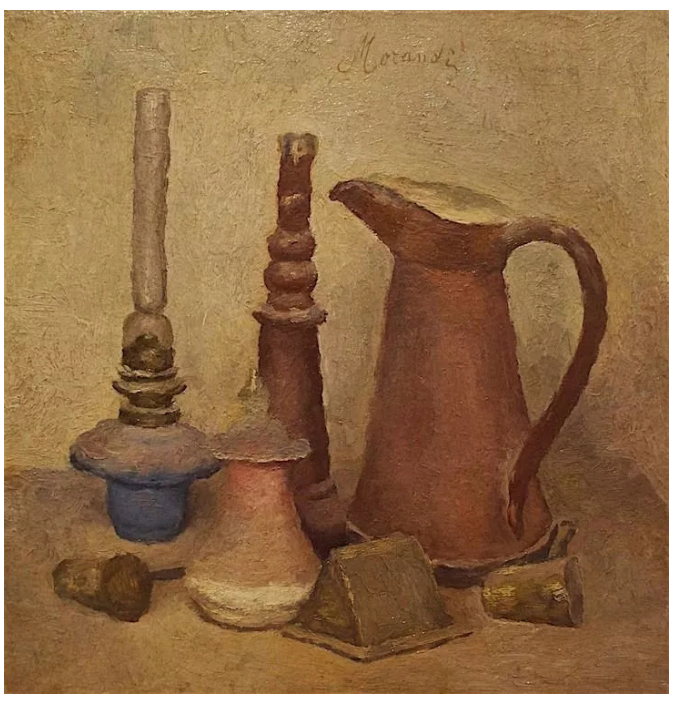

Figure 2. Morandi's painting B

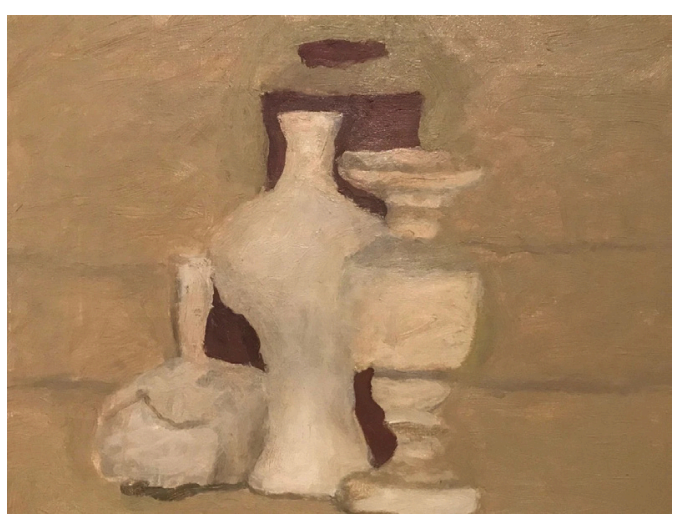

Figure 3. Morandi's painting C

\subsection{The role of emotion}

Ristowell says in Review of the History of Modern Aesthetics: "Beauty is the expression of emotion; and all such expressions are beautiful without any exception", artwork is not only the presentation of a picture, but also should be a carrier of emotional communication. From the use of contour lines in the historical development, we can see that contour lines not only help the author to outline the shape of the object, it also changes with the communication of the author's subjective intention. By using the inner and outer contour lines in different ways, the painter expresses the emotion and connotation he wants to convey when painting, and by presenting the inner contour lines in different ways through color division and structural expression, the painter sublimates the final effect of the picture and its emotional expression. In Giacometti's and de Kooning's drawings and paintings, the line is a typical work that expresses emotions through repetitive techniques. His sketches are like transparent structures built on paper. In addition to the technique, the many lines gathered together form a powerful shape, and the use of both outer and inner contour lines gives the whole picture a tangled and hideous power. The images shaped in the oil painting "Caroline" and the sketch "Portrait Exercises 4" go deep inside, showing not only the intimidating figures, but also the disturbing emotion that fills the whole picture. The Dutch-American painter de Kooning is one of the soul figures of Abstract Expressionism, and he has incorporated the concept of radical art into his art. The effect is inaccessible to the viewer, and de Kooning's lines guide the viewer, saying: "When I was painting, I didn't know what to expect. I don't know what will come out of it myself, but I think that's the most interesting thing, to have things never be sure, to be 'unpredictable', and the same is true of life and world affairs". He tries to awaken in people's hearts a sense of inner connection with all living things.

In contrast to Giacometti and de Kooning, Morandi's works are mostly related to his own life experiences, for example, 
between 1900 and 1920, when he was studying accumulation, i.e., entering the preparatory class of the Academy of Fine Arts in Bologna, when Cubism was prevalent and can be seen in his works, until the turning point of Morandi's artistic career in 1950, when he painted a series of paintings between 1940 and 1964. In the 24 years between 1940 and 1964, he painted thousands of works, and through the years, the images became particularly subdued, showing an unusually calm effect. Despite the proliferation of award-winning works, he did not change his style. Instead, he continues to explore the peaceful place in his heart. He once said, "I have always thought that there is nothing more abstract and unreal than the world we see. All the things we perceive in the material world are not as we see and understand them. The qualitative nature of matter certainly exists, but it does not have any meaning that we attach to it. Only we can know that a cup is a cup and a tree is a tree

..." These seemingly insignificant still lifes hold all of Morandi's 'love', a perfect combination of abstraction and figuration in the paintings.Although they look very fresh and casual, they actually convey a deep meaning of tranquility and distance. We can feel a strong sense of form in his watercolor works, and he has taken a unique route in both composition and formmaking. The sure brushstrokes and the control of positive and negative shapes reflect Morandi's ordinary and indifferent understanding, which is not only a reflection of the painter's heart, but also a quiet view of everything in the universe that lasts forever and never gets tired of seeing.

\section{Conclusion}

Morandi is a unique Italian art master of the 20th century, who gave his paintings a depth of meaning with his unique perspective. His works are small in size, moving to write static, briefly summarizing, deleting unnecessary details, and showing the most essential side of things to the viewer through the expression of the individual characteristics of the objects. The contour line is a crucial part of the painting, whether it is the outer contour line or the inner contour line of the structure and color division of the form, all of which are carefully considered by Morandi. In my opinion, in Morandi's still life paintings, his grasp of the inner and outer contour lines has reached a considerable level, and the beauty and strong emotions conveyed by the contour lines to the viewer add a lot of color to the effect of the picture. The contour line is like the foundation of a building, and all other contents and adjustments need to be attached to the inner and outer contour lines, and only with it can other contents be created. In this paper, we analyze the role of contour lines in Morandi's paintings, rationalize and summarize their usefulness, and use them flexibly in our own paintings, so that the viewer can experience the feelings that the author wants to express from his works.

\section{References}

[1] Michael Semff, Morandi, Dep Legal 187045/02, Tiragem/Print run:1000, Now. 2002.

[2] Dictionary Editorial Committee. Dictionary of the sea[M]. Shanghai: Shanghai Dictionary Publishing House, 1973: 3073 .

[3] Leonardo da Vinci. Da Vinci on painting[M]. Nanning: Guangxi Normal School Publishing House, $2003: 162$.

[4] [US] Rudolf Arnheim. Visual Thinking, Translated by Knee Shouyao[M]. Guangming Daily Publishing House, 1987: 146-147.

[5] Ristowell. Review of the History of Modern Aesthetics, Translated by Jiang Kong Yang[M]. Shanghai. Shanghai Translation Publishing House, 1980.

[6] He Zhengguang. The Complete Collection of World Famous Painters De Kooning[M] Shijiazhuang, Hebei Education Press, 2005.

[7] Xu Jiang, Jiao Xiaojian. Selected Writings on Figurative Expression Painting[M]. Beijing: China Academy of Art Press, 2002: 105. 